\title{
Microcontroller-based 4 Quadrant Trainer for Drives
}

\author{
${ }^{1}$ Santosh Verma, ${ }^{2} \mathrm{C}$. Khare, ${ }^{3}$ Sanjay Verma, ${ }^{4}$ Ajay Sharma \\ ${ }^{I}$ Electrical \& Electronics Department, M.I.T. INDORE/R.G.P.V. University Bhopal, India \\ ${ }^{2}$ Electrical \& Electronics Department, S.V.I.T. INDORE/R.G.P.V. University Bhopal, India \\ ${ }^{3}$ Electronics \& Communication Department, S.V.I.T. INDORE/R.G.P.V. University Bhopal, India \\ ${ }^{4}$ Electronics \& Communication Department, S.V.I.T. INDORE/R.G.P.V. University Bhopal, India
}

\begin{abstract}
This paper describes the development of an experimental four quadrant drive trainer for speed control of dc motor drive. A firing scheme based on a microcontroller to control an anti parallel connected single phase thyristor dual converter is presented. The dc motor drive consists of a $0.25 \mathrm{~h}$. p. separately excited $d c$ motor. This trainer is used by the students in the electric drives laboratory to control the speed of dc motor under different load conditions and understand the working of motor in all four quadrants. The control strategy used is as simple as possible that helps even the naive users to understand basic four quadrant operation. Experimental results show that the proposed scheme gives good dynamic and static performance for the speed control systems and practical knowledge for the students.
\end{abstract}

Keyword: - Microcontroller, ZCD, SCRs, Dual converter, Pulse-Transformer, D.C. motor, current sensor.

\section{INTRODUCTION}

In order to create the undergraduate engg. students natural interest on computer control it has been thought to develop a variable speed dc motor drive system using microcontroller based controller at S.G.S.I.T.S, Indore. This is done by presenting the state of art and current technology such as application of computers and power electronics for data acquisition and control of electric machinery. Some universities have also, introduced application of these devices in their electric machinery laboratory to make the experiments up to date and more efficient. i.e.[1] - [5].

The objective of this paper is to explore the approach of designing and developing a microcontroller based trainer for speed control of dc motor in order to keep better flexibility and versatility at S.G.S.I.T.S., Indore. This has been done with a view that Students can perform a variety of experiments in order to replenish their knowledge on thyristor drives, software programming and to test few aspects of modern control theory which they study in their course curriculum.

\section{SCHEME DESCRIPTION}

The simple block diagram of the system is shown in fig. 1 below. Fig. illustrates the basic blocks of the drive and how they interact.

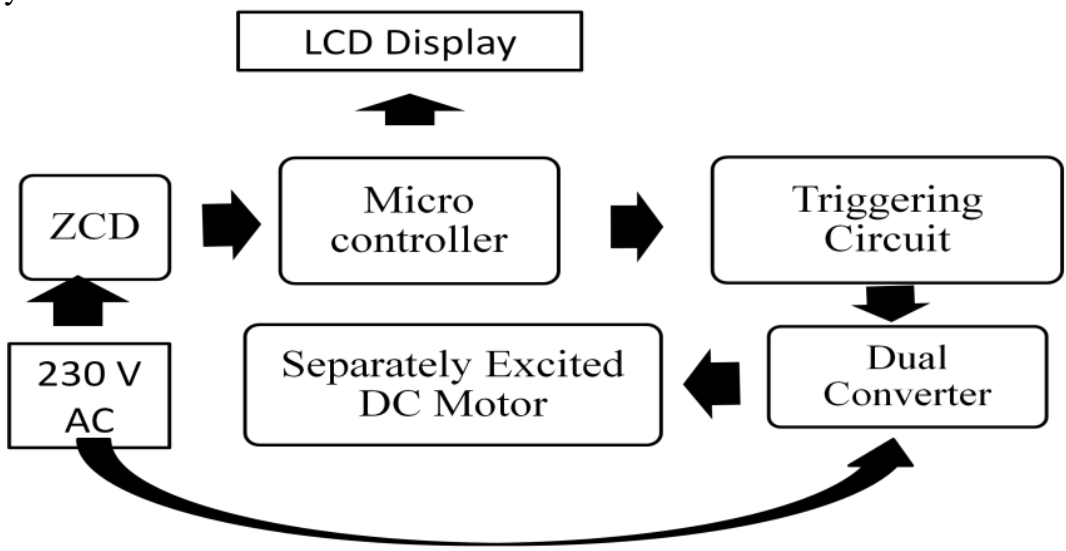

Fig. 1 System block diagram

In proposed scheme, a dual converter used for four quadrant operation of the d.c. motor. There are two converter groups, one positive group and the other negative group. When two thyristors of a particular group conduct simultaneously, then the load current flows. A microcontroller is used for the firing angle control of the dual converter. The thyristor of the converter in conduction should receive the firing pulses for either modes of continuous and discontinuous operation. Two thyristors should receive the pulses at a time. The firing signal 
contains several pulses. The firing pulses so obtained turn the thyristor ON reliably. Through the matrix keypad, the instructions are given by the user to the microcontroller, where the information is processes. The conduction of the positive group converter or negative group converter is decided from the above information and accordingly firing pulses are given to either positive group converter or negative group converter. The microcontroller also displaying information about firing angle and direction of rotation of the d.c. motor. The zero cross-over of the supply voltage is detected by the Zero cross over detector using same supply voltage used for the incoming supply for the dual converter. The firing delay angle is calculated with the help of this zero cross over detector.

\section{MICROCONTROLLER BASED DIGITAL CONTROLLER}

These part of trainer unit uses a master microcontroller (AT89C8051), a slave microcontroller (AT89C4051) in conjunction with interactive display control facilities. (See fig-3). These controllers would perform the following tasks by programming:-

a. The operator should have the facilities to set the firing angle through the matrix key board from low values to higher values up to the maximum limit in close steps.

b. The function of slave micro - controller is to overcome the slow information processing of the master microcontroller.

c. For the synchronizing purpose a frequency counter is used to measure the frequency of the input signal.

d. The ZCD produces a pulse at each zero crossing of the ac input signal. These pulses reset the master micro controller and initialize the firing delay calculation.

e. An LCD display with matrix keypad is used to display the firing angle and direction of rotation of motor i.e. clockwise or anticlockwise.

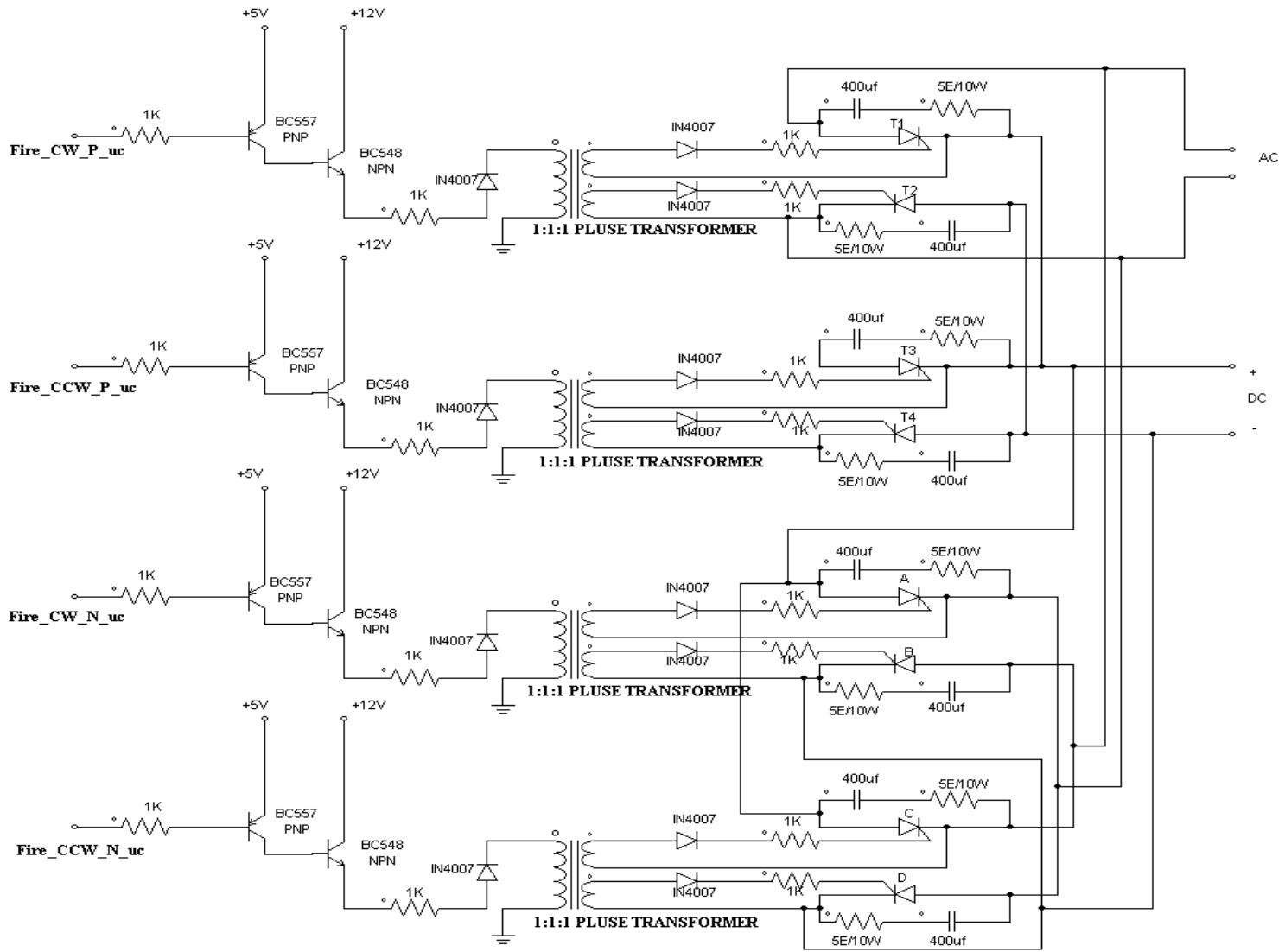

Fig. 2 Hardware Circuit Diagram for Drive System 


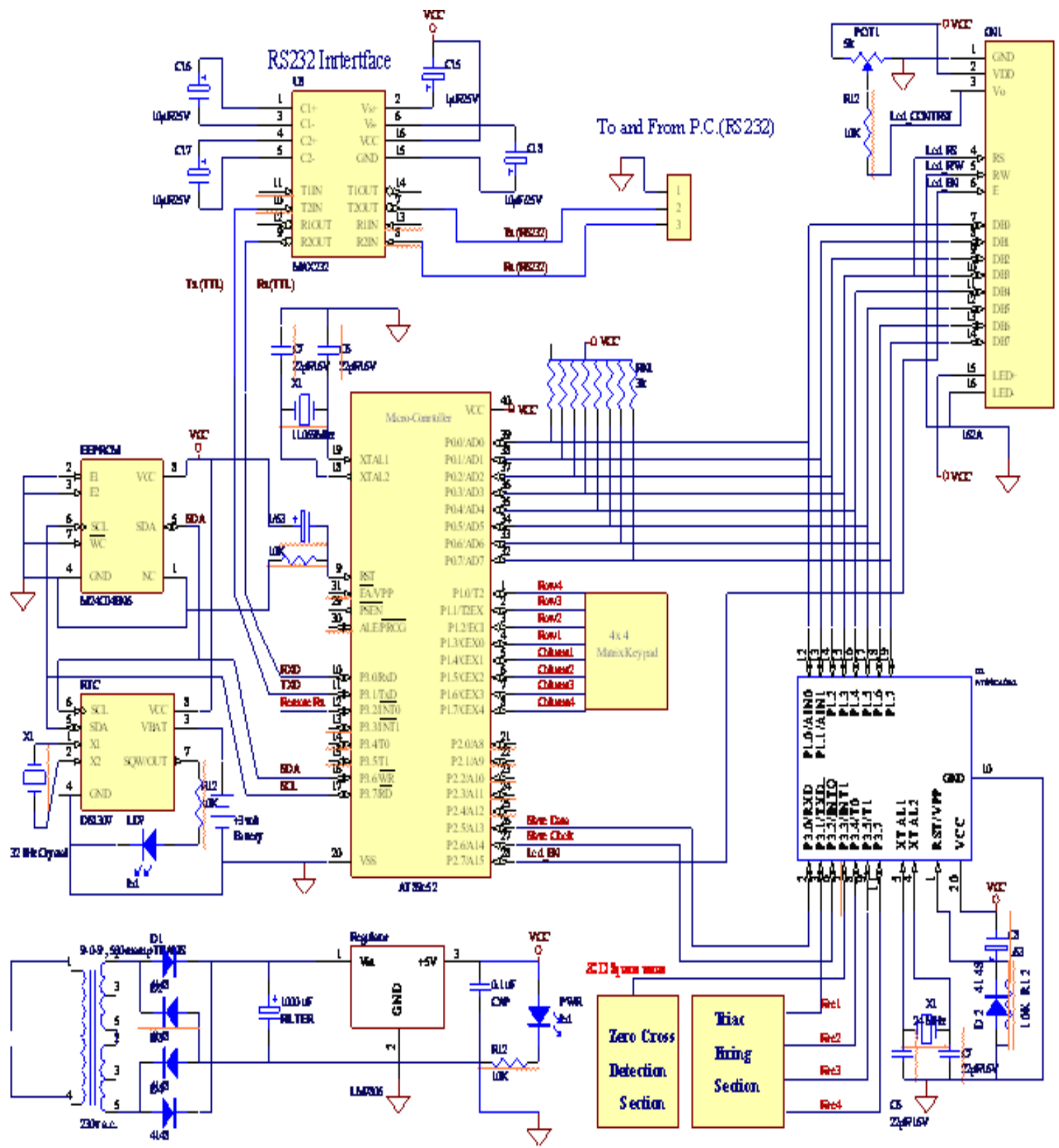

Fig. 3 Controller Circuit Diagram

IV. SOFTWARE ALGORITHM

In the presented trainer unit ATMEL's AT89C51 single chip microcontroller is used to implement the direct digital control for the thyristor drive system. The functions of controller can be divided as initialization, control \& pulse generation and display. In the initialization function the program is initialized and tests are made for proper operating conditions. These signals are used to monitor the system. In the control \& pulse generation function the input data of the inner and outer loops are processed to determine the interrupt level and to control the output current respectively. In the interrupt routine, which converter (positive converter or negative converter) will be turned on/off are selected. The firing pulses for the pairs of thyristor of selected converter are generated by the interrupt routine. As this, trainer unit is designed to operate in non-circulating mode of operation of dual converter, therefore a delay of $20 \mathrm{~ms}$ is provided for selection of another converter. The display function has a loop structure in which the firing angle for converters is calculated and displayed on the LCD display system. 
Microcontroller-based 4 Quadrant Trainer for Drives

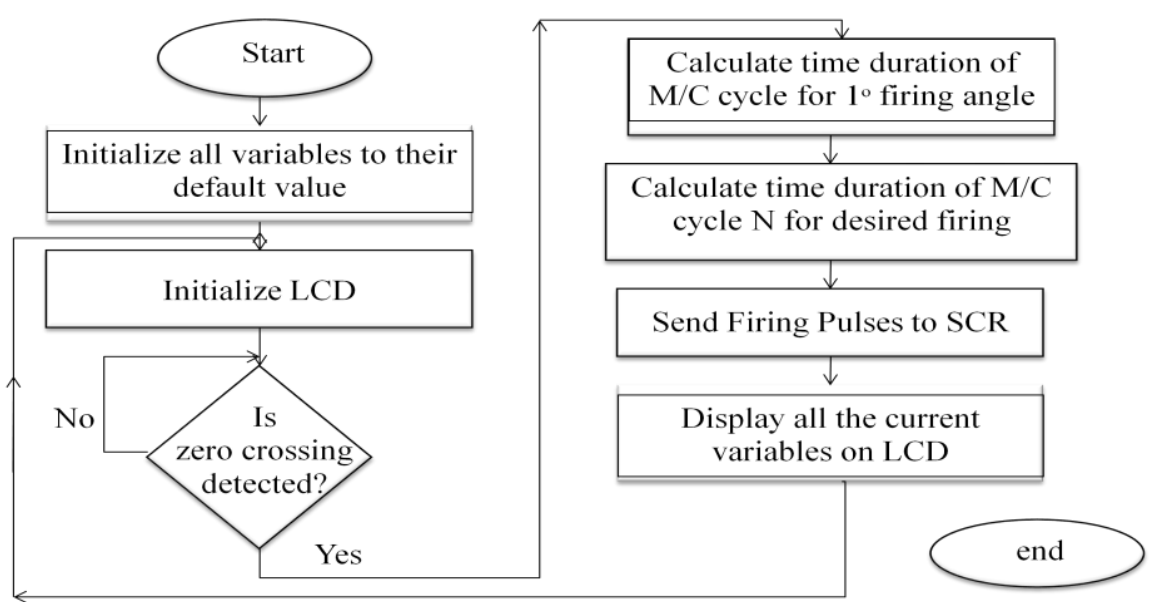

Fig. 5 Flow Chart for Control Scheme

The students can also see the direction of rotation of the motor and the frequency of input supply from the display function.

The program can be interrupted by the user at any time to change the reference speed. This is done by using increment or decrement key on the matrix keyboard which is programmed to cause a go to statement. This command will interrupt the existing software operation loop and will return the flow point in the flow chart where new desired speed is requested for the motor (see fig 5). The program will then continue as explained to adjust the motor speed to its new desired value. These preprogrammed, but user made just allow the program flexibility which is a feature of this interactive system.

\section{EXPERIMENTAL RESULTS}

A $1 / 4$ h.p. separately excited dc motor $(230 \mathrm{~V}, 1 \mathrm{~A}, 1500 \mathrm{rpm})$ is driven by the anti-parallel connected single phase thyristor dual converter described above. The complete experimental setup is shown in fig. 6 . The waveforms of armature voltage at various firing angles like $30^{\circ}, 60^{\circ} .90^{\circ}$, etc. are recorded by a storage oscilloscope. The microcontroller is programmed to provide a sequence of firing angles. Fig. 7 shows the waveforms under various firing conditions. These waveforms are obtained in non-circulating mode of operation.
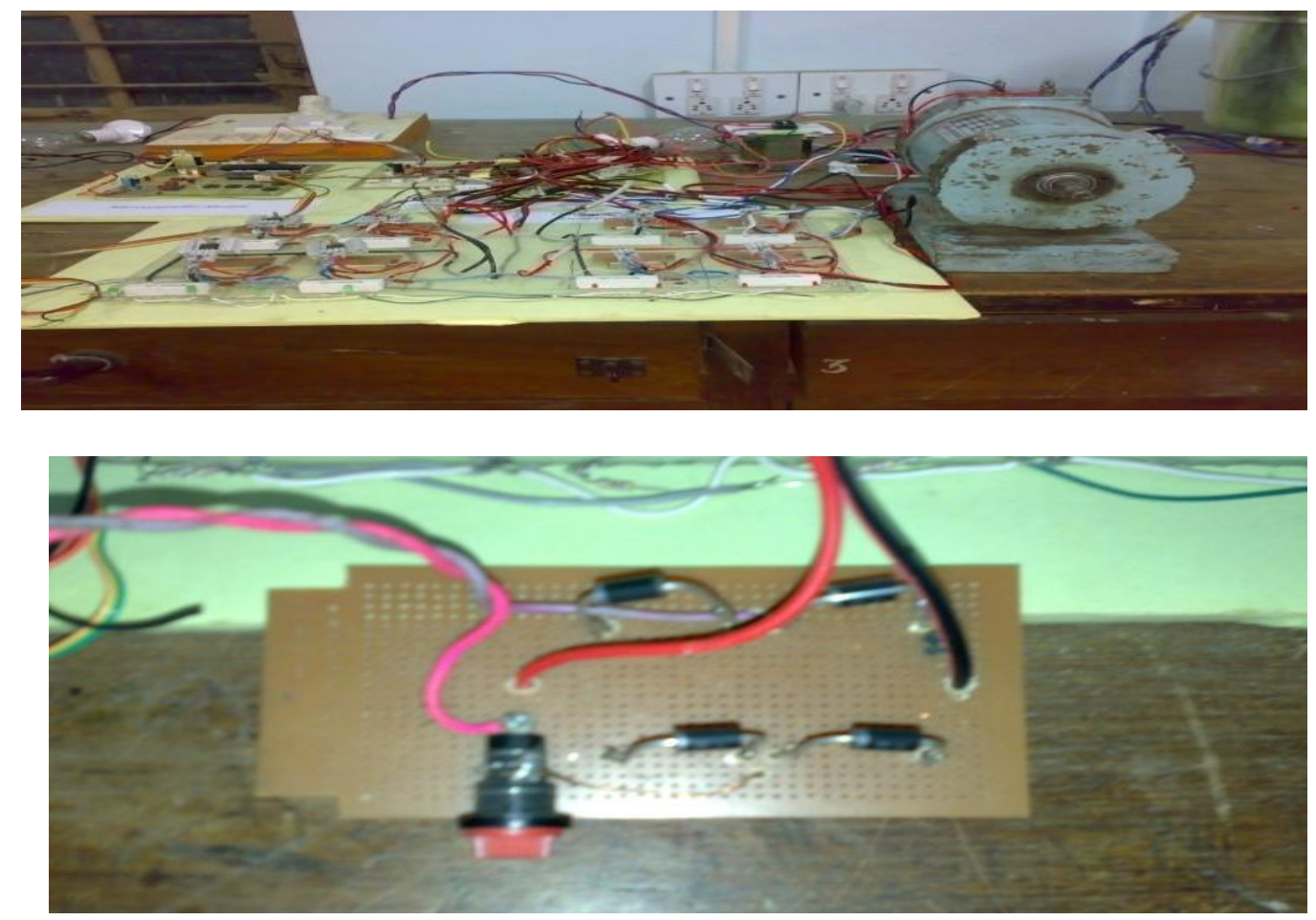

Fig. 6 Complete setup of Hardware 


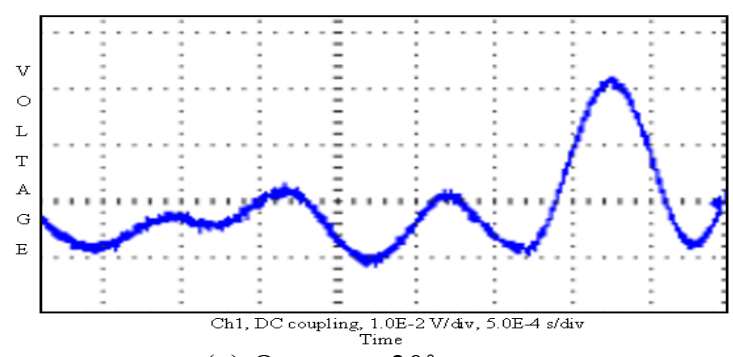

(a) Output at $30^{\circ}$

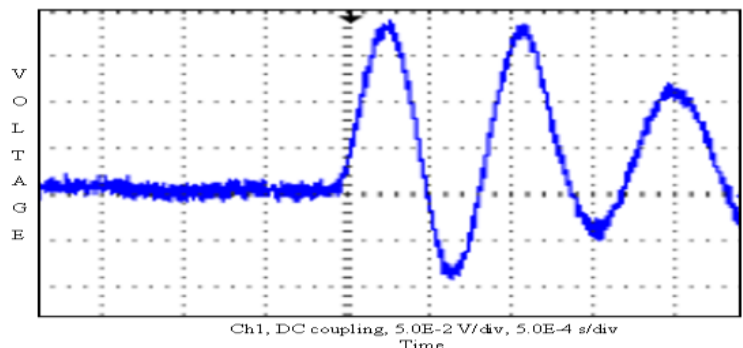

(c) Output at $90^{\circ}$

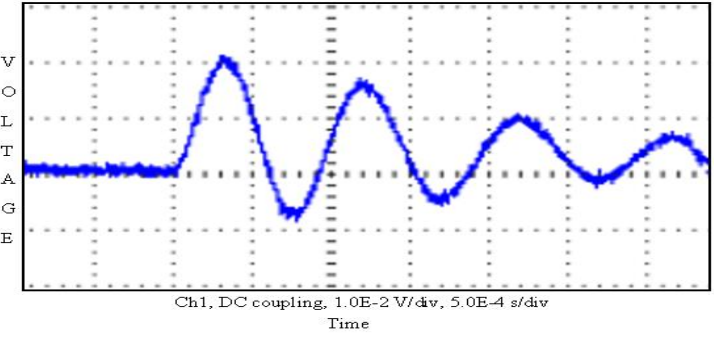

(b) Output at $60^{\circ}$

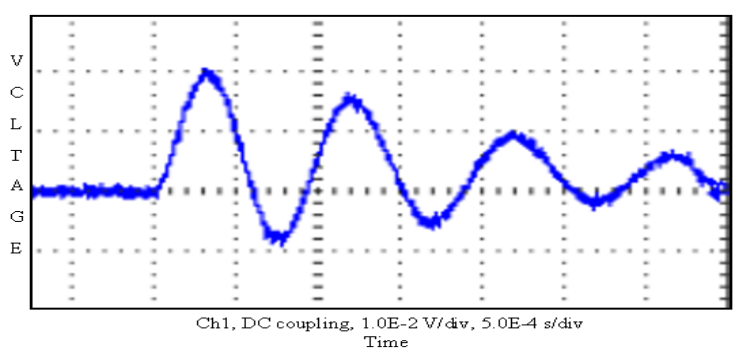

(d) Output at $120^{\circ}$

Fig. 7 Waveforms of Armature Voltage

\section{CONCLUSION}

The microcontroller based dc motor speed control system was achieved in a manner understandable to the junior electrical engineering students without background in control theory. The trainer integrates a digital controller and a drive system for explaining the operation. Experience of the electrical engineering juniors with the system has been very good and has stimulated considerable interest among them in the application of power electronic circuitry and computers in control of electric machinery. Clearly, addition of such instrumentation and control units to the drives laboratories and emphasizing the application of these devices in today's industry will help in better presenting the serious and challenging image of electric machines and their applications to the students.

\section{Proceedings Papers:}

\section{REFERENCES}

[1] Teerawat Thepmanee, Sawai Pongswatd, Prapart Ukakimapurn, and Kitti Tirasesth, Department of Instrumentation Engineering, Faculty of Engineering, King Mongkut's Institute of Technology Ladkrabang, Bangkok, Thailand , "The Technique to Generate Firing Signal of Converter for Linear DC Output”, The University Electro-Communications, Japan ,SICE Annual Conference 2008 August 20-22, 2008.

[2] Molevkutty George , "Speed control of Separately Excited DC motor", American Journal of Applied Sciences 5 (3): $227-233$, 2008.

[3] Feraga Chams-Eddine, Bouldjedri Abdallah and Yousfi Ali, "Uniform pulse-width modulation (UPWM) three phase four quadrant ac-dc converter fed dc motor drive", Asian journal of Information Technology 5(7): pp: 761-766, 2006.

[4] K. M. Rahman1, M. A. Choudhury2 and Tofayel Ahmed Zulfikar3 1Department of Mechatronics, International Islamic University Malaysia "an AT89C51 microcontroller based control circuit for dual three phase controlled rectifier" 3rd International Conference on Electrical \& Computer Engineering ICECE 2004, 28-30 December 2004, Dhaka, Bangladesh.

[5] Kim Tae- Woo, Kim Hack-Sung, "New ZCS PWM Converter with operating a dual converter", IEEE, 2003.

[6] Tipsuwanpom V., Sum-Im T., Suesut T., Piyarat W. Sawaengsinkasikit W. , "New Technique Controlling of 4-Quadrant DC Motor Drive", IEEE 2000

[7] S. P. Chowdhury, Dr. S. K. Basu, R. Mondal, "A model of microcontroller based speed control of a dc motor with interactive di splay", IEEE Trans. On Power system, vol.7, No. 1, Feb. 1992.

[8] S. J. Ranade, "An automated data acquisition and processing system using personal computers for an undergraduate electric machinery laboratory," presented at the IEEE/PES 1988 Winter Meeting, New York, NY, Jan. 31-Feb. 5, 1988, paper 88 WM $055-6$.

[9] A. H. M. S . Ula and J. M. Wu, "Design and demonstration of a microcomputer controller for an industrial sized DC motor," IEEE Trans. Energy Conv., vol. EC-3, pp. 11 1-1 15, Mar. 1988.

[10] T. K. M. Babu and C. V. Nayar, “A microprocessor controlled dc drive,” Internat. J. Elect. Eng. Educ., vol. 23, no. I , pp. 43-50, Jan. 1986.

\section{Books:}

[11] G.K Dubey, Fundamental of Electrical Drive (Narosa publishing House: 2002).

\section{Web site:}

[12] http://www.microchip.com

[13] http://www.sunrom.com 